Oral Section

\title{
High Risk Human Papillomavirus genital infections in asymptomatic population: effectiveness of Micro- Immunotherapy
}

\author{
Sandra Mazzoli ${ }^{1}$, Tommazo $\mathrm{Cai}^{2}$, Francesca Meacci ${ }^{1}$, \\ Patrizia Addonisio ${ }^{1}$, Pierre Dorfman ${ }^{3}$ \\ ${ }^{1}$ STDs Centre, S.M.Annunziata Hospital, Firenze, Italy \\ 2Department of Urology, Santa Chiara Hospital, Trento, Italy \\ 3Labo'Life, Gembloux, Belgium
}

\begin{abstract}
Background: persistent infection with high-risk human papillomavirus (HR-HPV) is the primary cause for the development of various anogenital cancers in females and males. Most infections are either latent or subclinical and the majority occur as asymptomatic. HPV infections are not currently treatable by antiviral compounds. Micro-immunotherapy (MI) medications using high dilutions of cytokines and specific nucleotide sequences have been developed to treat targeted viral infections and are currently prescribed in medical practice as immune regulators: 2L®PAPI (Labo'Life) is indicated for HPV infection and may represent a new therapeutic approach.
\end{abstract}

Aims: this exploratory study was to assess the effectiveness of $2 \mathrm{~L} \otimes P A P I$ on HPV infection eradication in HRHPV infected asymptomatic patients attending an STD Centre in a long-term microbiological follow-up population survey.

Methodology: adult patients of both genders, diagnosed with HR-HPV infection, with no evidence of symptomatic HPV or anogenital cancer, were followed during a 2 year-period (2009-2010). Selected patients had not previously been vaccinated for HPV or treated with medications having an impact on the immune system. HPV testing was performed on biological samples using PCR detection (Innogenetics, Italy). In addition, detection of E6/E7 mRNA of five carcinogenic HPV types was performed by EasyQ HPV (BioMerieux, Italy). HPV-positives were requested by their urology specialist to take 2LßPAPI (composition in table 1) during 4 months (1 caps/day by sublingual route). Globally 46 patients were followed: 23 treated with MI medication, and 23 not treated.

Results: one third of selected patients were lost at the control visit (15/46). At the end of the study period, HR-HPV negativity was observed in 50\% (8/16) of patients under MI medication in comparison with only $7 \%$ $(1 / 15)$ of the non treated patients who were HPV-DNA negative at the follow-up visit ( $\mathrm{p}=0.01071$, Mid-P exact test). This result is in accordance with our previous results which showed long lasting persistence of HR-HPV infection in a male cohort.

Conclusions: the relevant percentage of lost patients at follow-up reflects the scarce information and awareness of this infection within asymptomatic people in Italy. 2LßPAPI was efficient in eradicating $50 \%$ of 
HR-HPV infections in treated patients, including $60 \%$ of HPV-16. These promising data emphasize the importance of redirecting immune responses in viral infections.

Table 1: 2L®PAPI composition

\begin{tabular}{|l|c|}
\hline Compounds & Dilutions \\
\hline Interleukin-1 (IL-1): & $17-10 \mathrm{CH}^{*}$ \\
\hline Interleukin-2 (IL-2): & $17-10 \mathrm{CH}$ \\
\hline Interferon-a (IFN-a): & $17-10 \mathrm{CH}$ \\
\hline SNA-HLA II: & $16-10 \mathrm{CH}$ \\
\hline Ciclosporin A (CsA): & $7-10-17 \mathrm{CH}$ \\
\hline Ribonucleic acid (RNA): & $18-10 \mathrm{CH}$ \\
\hline SNA-PAPI: & $16-10 \mathrm{CH}$ \\
\hline
\end{tabular}

* CH: Centesimal Hahnemannian (1/100)

Keywords: Human papillomavirus; HR-HPV-DNA testing; Micro-Immunotherapy, 2L®PAPI

\section{(c)) BY-NC-ND Licensed to GIRI}

Support This work has been partially supported by a grant from Medicap Holding International Ltd, Sittingbourne, UK Conflict of interest: P. Dorfman is Medical Director at Labo'Life

Received: 01 June 2012; Revised: 12 August 2012; Published: 30 September 2012.

Correspondence author: Sandra Mazzoli, mazzoli49@yahoo.com

How to cite this article: Mazzoli S, Cai T, Meacci F, Addonisio P, Dorfman P. High Risk Human Papillomavirus genital infections in asymptomatic population: effectiveness of Micro-Immunotherapy. Int J High Dilution Res [online]. 2012 [cited YYYY Month dd]; 11(40):134-135. Proceedings of the XXVI GIRI Symposium; 2012 Sep 20-22; Florence (Italy). GIRI; 2012; Available from: http://www.feg.unesp.br/ ojs/index.php/ijhdr/article/view/566/614 